\title{
Estrategias jurídicas para afrontar el acoso laboral en el Ecuador
}

\section{Legal strategies for facing labor harassment in Ecuador}

\author{
Edwin Leonardo Tello Yandún ${ }^{1 *}$ y Carlos Miguel Yuquilima Niola ${ }^{1}$ \\ ${ }^{1}$ Universidad Católica de Cuenca, Ecuador \\ *etelloy@ucacue.edu.ec
}

DOI: https://doi.org/10.26871/killkanasocial.v4i3.208

\begin{abstract}
Resumen
En el presente trabajo se analiza al acoso laboral enfocado desde el ámbito Constitucional, Laboral, Civil, Penal y Procesal Civil Ecuatoriano, aportando soluciones acerca de este grave problema social y jurídico que oprime al trabajador ecuatoriano, todo aquello imbuido por acosadores laborales que les interesa que haya falta de socialización e interés social sobre el acoso laboral y su nefastos efectos en el país, por lo que se trata de minimizar los daños causados por el grave problema del acoso laboral dentro de la sociedad trabajadora ecuatoriana, debido a que en la actualidad el acoso laboral está representando un verdadero atentado contra principios y derechos constitucionales principalmente como el de la vida, libertad, dignidad, trabajo, no discriminación y protección familiar, al acoso laboral se lo ha tratado como un problema sujeto de investigación de este estudio por lo que se ha tratado a través de su conceptualización el identificarlo, Clasificarlo, darle una tipología, evidenciar sus consecuencias para finalmente poder proponer contramedidas pre legales y legales cuando se está frente al acoso labora en el Ecuador. Así al ser un problema producido por su desconocimiento, no solo que permite una serie de abusos y atropellos que desencadenan en conflictos laborales que trascienden llegando inclusive a afectar al individuo en su integridad física y psicológica, honorabilidad, salud, familia y a todo el entorno en el que este se desenvuelve, ya que el acosador queda impune y el acosado en indefensión, aparte de que como dato curioso en el Ecuador hasta la fecha no existe una denuncia tramitada por acoso laboral que haya prosperado positivamente. Es por ello que existe la imperiosa necesidad de dar a conocer, ¿Qué puede hacer una persona cuando está frente al acoso laboral en el Ecuador?.
\end{abstract}

Palabras clave: Acoso laboral, mobbing, derecho procesal laboral.

\begin{abstract}
In the present work we analyze labor harassment focused on the Constitutional, Labor, Civil, Criminal and Ecuadorian Civil Procedure, providing solutions about this serious social and legal problem that oppresses the Ecuadorian worker, all that imbued by job harassers that interest them that there is a lack of socialization and social interest about workplace harassment and its harmful effects in the country, which is why it is a matter of minimizing the damage caused by the serious problem of labor harassment within the Ecuadorian working society, because currently Workplace harassment is representing a real attack against principles and constitutional rights mainly as life, freedom, dignity, work, nondiscrimination and family protection, harassment at work has been treated as a problem under investigation of this study so that it has been tried through its conceptualization to identify it, to classify it, to give it a typology, evidencing its consequences to finally be able to propose legal and legal countermeasures when faced with harassment in Ecuador. Thus being a problem caused by their ignorance, not only allowing a series of abuses and abuses that trigger labor conflicts that transcend reaching even affect the individual in their physical and psychological integrity, honor, health, family and the entire environment in the one that unfolds, since the harasser remains unpunished and the harassed in defenselessness, apart from that as a curious fact in Ecuador to date there is no complaint filed for labor harassment that has prospered positively. That is why there is an urgent need to make known, ¿What can a person do when faced with workplace bullying in Ecuador?.
\end{abstract}

Keywords: Labor harassment, mobbing, labor procedural law.

\section{Concepción del acoso laboral}

Revisando las palabras acoso laboral en el diccionario se encontró lo siguiente: “Acoso" es la acción de acosar que viene del antiguo cosso, que significa carrera, y es el incitar de forma pertinaz a alguien con martirios o amonestaciones y mientras que "Laboral" viene de la palabra labor que a su vez se deriva del latín, òris, que es la acción y el efecto de trabajar.

Para el Dr. Heinz Leymann Psc. Ped., Psicólogo Alemán, que fue el pionero en desarrollar el estudio psicológico sobre el mobbing o acoso laboral, encontró un tipo de comportamiento singular hostil conocido como hostigamiento laboral por largo tiempo en empleados y en 
sus lugares de trabajo, en la actualidad el acoso laboral es conocido como el síndrome de Heinz Leymann y este proviene de las acciones hostiles e ilegales de terceros.

El acoso laboral en la legislación ecuatoriana actual se lo encuentra regulado en la Ley Orgánica Reformatoria a la Ley Orgánica del Servicio Público(Asamblea Nacional del Ecuador, 2017) y al Código del Trabajo para Prevenir el Acoso Laboral, y se lo considera como una conducta ilegal contra la dignidad humana, que es ejercida reiteradamente, constituyéndose en un acto continuo y lesivo, que se da en el lugar de trabajo, en cualquier momento, en contra de una de las víctimas que son parte en la relación laboral o entre trabajadores, que son causantes en la víctima de deterioro físico o psicológico a través de ofensas, deshonras o que amenace y lesione su entorno laboral incluyendo la filiación sindical y gremial.

\section{Modus operandi del acosador laboral}

Entre los más comunes se tienen los siguientes:

1) LA DESTRUCCIÓN LAS REDES DE COMUNICACIÓN DE LA VÍCTIMA.- Consiste en que la víctima debe de estar incomunicada quedando en estado de indefensión, esto se obtiene con cambios constantes en injustificados de actividades o de lugares en el mismo trabajo, escudándose en la "necesidad institucional" y va más allá, ya que esta incomunicación se extiende a todos los amigos y conocidos de la víctima dentro del trabajo, imposibilitando a la victima de responder ante burlas, menosprecios, o quejas de cualquier índole.

2) LA DESTRUCCIÓN DE LAS REDES SOCIALES DE LA VÍCTIMA.- Consiste en incomunicar a la víctima con los demás trabajadores, impidiendo que la víctima haga nuevos amigos y así pueda encontrar adeptos para enfrentar y aplacar el hostigamiento laboral causado por el hostigador, y si el lugar de trabajo es un zona enemiga, es algo lógico que la víctima acabe por desertar o renunciar al trabajo.

3) LA DESTRUCCIÓN DE LA REPUTACIÓN, VIDA PERSONAL O PROFESIONAL DE LA VICTIMA.- Consiste en que a través de rumores malicioso e insanos, sátiras públicas destructivas, se le atribuya a la víctima fallas y errores en la realización de su trabajo, dándose también la situación de que a veces el acosador, se adjudica el buen trabajo elaborado por su víctima, luciéndose con trabajo ajeno, causando en la victima baja autoestima y desgaste psicológico laboral.

4) LA DESTRUCCIÓN DEL PROFESIONALISMO LABORAL DE LA VÍCTIMA.- Consiste en que la víctima al estar en una situación desigual frente al acosador, este siempre tiene la ventaja para destruir el profesionalismo laboral de su víctima, a través de disposiciones mandando a realizar tareas imposibles de realizarlas lo que provoca en la víctima sanciones administrativas, o de la misma manera dejándole sin tarea alguna o también valiéndose de burlas de la prescindibilidad de su víctima en el trabajo.

5) LA OBSTRUCCIÓN A LA CAPACITACIÓN DEL PERSONAL.- Consiste en toda actividad que frene o lo que es peor obstruya la capacitación profesional del personal, que no se provea los recursos necesarios para la ejecución de una buena labor en el trabajo, con la intención de destruir la credibilidad profesional y el buen nombre de la víctima.

Estos 5 puntos son muy generales, ya que en la práctica laboral pueden presentarse nuevas formas de acoso laboral avocadas a un solo objetivo la culminación de la relación laboral de la víctima de acoso laboral.

\section{Tipos de acoso laboral}

Para el Dr. Heinz Leymann el acoso laboral son de tres tipos:

1) El Acoso Horizontal.- Se da entre trabajadores de igual jerarquía.

2) El Acoso Ascendente.- Se da entre trabajadores de desigual jerarquía y la víctima acosada es un jefe.

3) El Acoso Descendente.- Se da entre trabajadores de desigual jerarquía cuando el victimario acosador es el jefe que hostiga a un subalterno o grupo de subalternos.

Mientras que en el Ecuador se evidencian dos tipos de acoso laboral:

a) El Acoso Horizontal.- Se da cuando los sujetos laborales son de igual grado jerárquico.

b) El Acoso Vertical.- Se da cuando los sujetos laborales son de desigual grado jerárquico.

ACOSO HORIZONTAL.- Es el producido por compañeros de trabajo acosadores, de un mismo nivel jerárquico en el trabajo, quienes producen varias acciones lesivas en contra de uno o varios trabajadores víctimas, con el o sin el consentimiento del patrono o de los mandos superiores, causando daño laboral a sus víctimas.

EL ACOSO VERTICAL.- En este se evidencia un sub clasificación:

a) ACOSO VERTICAL DESCENDENTE.- Es cuando el acosador se aprovecha de su nivel jerárquico superior, para prolongar el acoso laboral llevándolo al extremo, aprovechando el recelo del acosado a perder su trabajo.

b) ACOSO VERTICAL ASCENDENTE.- Es cuando la víctima que tiene un nivel jerárquico alto dentro del trabajo, es acosado y atacado por uno o varios de sus inferiores.

Los posibles indicios, consecuencia del acoso laboral que se darían en el trabajo son: El traslado administrativo, el cambio de cargos, la destitución, la desidia, la invalidez temporal o permanente para trabajar injustificadamente; consecuencias que pueden truncar a la víctima en el trabajo. 


\section{Posibles profesiones en las que generalmente se pre- senta el acoso laboral}

Las profesiones donde frecuentemente se presenta el acoso laboral son: En el personal administrativo público o privado, en los profesores investigadores y docentes de universidades públicas o privadas, en los docentes de primaria, secundaria o universidad, en los ingenieros de sistemas, en los auditores, en los médicos, en los cuidadores de guarderías y escuelas infantiles, en el personal de hotelería y turismo, en el personal de bancos e instituciones financieras, en oficiales de marina mercante y en las Ongs.

\section{Sugerencias preventivas para evitar y mitigar el aco- so laboral}

Analizados los estudios de Iñaki Piñuel (2003) en su obra Mobbing: Manual de autoayuda, frente al acoso laboral, se concluye las siguientes sugerencias:

- Identificar bien si es acoso laboral, informándose bien sobre este problema. Documentar, registrar y evidenciar las agresiones de que se es objeto, desde el inicio. Hacer públicas toda agresión recibida en intimidad o en secreto, comunicándolas a los compañeros, jefes, directivos, asesores, pareja, amigos, familiares o inspector de trabajo según sea el caso.

- Evitar el reaccionar ante estos ataques, inclusive con estallidos de furia en público. Teniendo aplomo tratando de controlar la furia y el rencor, ya que la rabia es mala consejera y socia del acosador.

- Hacer frente al acoso laboral pensadamente, por lo general esto hace replegarse al acosador, que es un cobarde. Siempre procurar una respuesta serena y pensada a las mentiras y críticas destructivas.

- Resguardar datos tanto físicos como digitales de documentos y archivos del trabajo y guardar bajo llave, desconfiando siempre del acosador. Evitar la incomunicación saliendo y enfrentando socialmente el acoso laboral.

- Rechazar la inculpación o la justificación de culpabilidad, por parte del acosador, convenciéndose de que no es culpa de uno. No intentar convencer o cambiar al acosador.

- No caer en la privación, contando siempre a otros de este acoso y hablarlo, comunicarlo, escribirlo, relatarlo, etc., haciéndolo público. Desarrollar la formación y capacitación profesional, por cuenta propia.

- No permitir el acosado laboral ser destruido psíquicamente y denunciar a su acosador. Solicitar desde el principio del acoso laboral asesoramiento psicológico y jurídico especializado.

- Elevar la autoestima autónomamente, como cura contra el acoso laboral. Siempre demostrar el tener un buen humor y paciencia.

- Permitirse desahogarse por el daño recibido, como cura psicológica. Perdonar al acosador después de ser castigado, como forma de liberación final.

\section{Denuncia del acoso laboral}

Las denuncias de acoso laboral en el Ecuador pueden presentarse en forma reservada o de forma pública:

De Forma Reservada.- Consiste en presentar la denuncia reservadamente a las autoridades de Recursos Humanos (área privada) y en la UARHS. (área pública), aplicándose el procedimiento sumario administrativo en la área pública o una investigación en la área privada, de fracasar estas vías procesales alternas se puede recurrir a la denuncia de forma pública.

De Forma Pública.- Consiste en presentar la denuncia a las autoridades públicas del Trabajo, pudiendo presentarse en dos fases: la fase administrativa (Inspector del Trabajo) y la fase judicial (Juez del Trabajo).

\subsection{La fase administrativa}

El inspector de Trabajo receptará, investigará y resolverá toda denuncia de acoso laboral, ya sea de oficio o a solicitud de parte, la cual deberá:

a) Evidenciar la presencia de la ilegalidad.

b) Valorar los actos que soportan la existencia del acoso laboral, para no ser confundida con otras figuras.

c) Valorar y examinar las pruebas que presenten las partes.

d) Reparar el problema dependiendo del nivel del daño causado, ya sea por medio de sanciones u otros medios alternativos como soluciones conciliatorias.

\subsubsection{Procedimiento ante el acoso laboral de forma pú- blica administrativa}

El procedimiento judicial aplicable ante el acoso laboral está contenido en la Ley Orgánica Reformatoria a la Ley Orgánica del Servicio Público y al Código del Trabajo para prevenir el Acoso Laboral, en los Arts. 8, 9 y 10 (Asamblea Nacional del Ecuador, 2017), en el que se ordena que en caso de soportar acoso laboral, realizado, cometido o permitido por acción u omisión del empleador sus representantes legales, posteriormente a la presentación de la petición del visto bueno, descenderá la apertura de una conciliación que regirá la autoridad laboral competente (inspector del trabajo), en la que serán oídos, además del que tenga algún interés en la denuncia, los dirigentes de los trabajadores y el empleador o su representante y la compensación monetaria será la establecida en el segundo inciso del artículo 195.3 del Código de Trabajo(Corporación de Estudios y Publicaciones, 2017), dependiendo de la gravedad del caso la víctima de acoso podrá pedir ante la autoridad laboral competente (Inspector de trabajo), las disculpas públicas del acosador, y en el caso de que el trabajador presente sospechas fundamentadas de haber sufrido acoso laboral corresponderá al empleador, el presentar excusas objetivas y razonables, suficientemente probadas, de las acciones adoptadas y de su proporción. En el caso del acoso laboral, la autoridad competente podrá ordenar que se efectúen las disculpas públicas del caso de quien cometió el acoso. 


\subsection{La fase judicial}

Cuando la víctima y la empresa no han podido llegar a un acuerdo en la Inspectoría de Trabajo o cuando ni siquiera se presentó el reclamo de acoso laboral en la Inspectoría del Trabajo, la víctima podrá reclamar en vía judicial ante uno de los Jueces de Trabajo, solicitando el reconocimiento de sus derechos laborales vulnerados, y así los jueces de trabajo después de analizar el problema laboral y subsumirle en la norma, emita una decisión a través de un Auto interlocutorio siempre precautelando los derechos de los trabajadores, Arts. 573 y 575 del Código de Trabajo(Corporación de Estudios y Publicaciones, 2017). En todo acoso laboral, siempre hay dos sujetos en esta relación, el activo y el pasivo.

Sujeto Activo (Acosador).- Son todas las personas que llevan a cabo acciones lesivas, de manera individual o colectiva en contra de una o varias personas del trabajo, de manera consciente o inconsciente, con el fin de conseguir su separación o descalificarlas frente a otros, para que se deslinde del trabajo, pudiendo ser un compañero o un jefe de trabajo.

El perfil de todo acosador laboral es el de narcisistas, que según Sigmund Freud es toda persona que se siente en suficiente capacidad de usar su gran poder sin ninguna responsabilidad para controlar de esta manera a otras personas, virtualmente a través de la fuerza inclusive, por las que se siente que amenazan su modo de vida y está dentro de una fantasía presuntuosa, en vez de vivir en la realidad, viéndose a sí mismo como un ser superior a sus compañeros y pretende ardientemente en serlo.

Sujeto Pasivo (Acosado).- Es todo trabajador o grupo de trabajadores a los cuales se les aplica actos, deliberados, lesivos, sistemáticos y repetidos por el acosador, los cuales afectan el desenvolvimiento profesional de la víctima en el trabajo, la cual debe sufrir actos lesivos de forma reiterada, sistemática y demostrable para ser considerado jurídicamente como acoso laboral.

Perfil del acosado laboral son personas que tiene una autoestima baja, muy trabajadora y además hacen las cosas bien, son creativos, siempre llevándose bien con todos, son muy sociables y afables, aumentando el riesgo de ser acosados por ser atractivos físicamente, son bien valorados por su excelente desempeño en el trabajo, tienen una sólida ética y moral; siempre cuestionan lo establecido de forma constructiva o cuando está algo no está bien y sin impórtales trabajar en equipo viéndolo como una oportunidad para mejorar su desempeño laboral tanto individual como colectivo.

\subsubsection{Procedimiento ante el acoso laboral de forma pú- blica judicial}

El procedimiento de forma pública inicia con la solicitud de la denuncia por acoso laboral a través de la presentación de una demanda sumaria, la misma que debe contener todos los requisitos legales y el anuncio de la pruebas de las que se dispongan, se la debe presentar en la oficina de sorteos para que se radique y sea calificada, de ser calificada como clara y completa, con la demanda calificada se procederá a citar a la parte demandada para que de su contestación y la reconvención conexa de ser procedente en máximo 15 días, de la contestación y reconvención se convocará a una audiencia única después de 15 días, en donde se presenta dos fases una sola audiencia, en la primera fase se practicara primero el saneamiento del proceso, segundo se fijara los puntos a los se contrajo la demanda y tercero la conciliación, de darse la misma termina el proceso, pero al no concretarse la conciliación se pasaría a la segunda fase en la cual primero se introducirán la pruebas al proceso y se practicaran la pruebas solicitadas de las partes comenzando con la parte actora y luego con la parte demandada, una vez practicada todas la pruebas, se receptaran los alegatos judiciales finales primero la parte actora y luego la parte demandada, al concluir con los alegatos el juez emitirá su auto interlocutoria, posterior a este se recibirá la sentencia en el casillero judicial, terminando el proceso, se puede recurrir a la apelación en la emisión de la sentencia de ser el caso y en tres día se llevara a cabo la audiencia en segunda instancia.

\section{Diferencias entre acoso laboral y estrés laboral}

El Estrés Laboral o Síndrome de "Burn Out"(World Health Organization, 1994), también se lo conoce como el Síndrome del Trabajador Quemado, que es una respuesta patológica propiciada por una exposición prolongada de estrés ante factores externos estresantes como los emocionales o interpersonales que se pueden presentar en el trabajo, esto incluye la ineficacia y negación de lo ocurrido, fatiga crónica, proporcionada por la relación directa en el cumplimiento del trabajo, diferenciándose por completo con el Acoso Laboral que se da en las relaciones interpersonales dentro del trabajo, y no necesariamente en la ejecución del trabajo, siendo causado por terceras personas, (compañeros de trabajo o jefes mediatos o inmediatos).

\section{Acciones judiciales frente al acoso laboral}

\subsection{Acciones judiciales laborales y penales}

Las acciones judiciales laborales que se podrían proponer podrían ser la del despido ineficaz que al ser declarado como tal y según lo ordena el Art. 195.3 del Código de Trabajo, se entenderá que la relación laboral nunca fue interrumpida por el hecho que la ha motivado y se ordenara el pago de las remuneraciones pendientes con el diez por ciento $(10 \%)$ de recargo y si la persona despedida decidiere, a pesar de ser declarado la ineficacia del despido, no continuar con la relación laboral, recibirá una indemnización compensatoria semejante al coste de un año del sueldo que venía recibiendo, además de la indemnización general que corresponda por despido intempestivo, y si el empleador se niegue a conservar en su cargo al trabajador despedido después de ordenado el reintegro inmediato del mismo en providencia inicial, o se estableció la ineficacia del despido a través de resolución judicial, este será sancionado con la pena establecida en el Art. 282 COIP 
(Corporación de Estudios y Publicaciones, 2015),, por el delito de incumplimiento de decisiones legítimas de autoridad competente con uno a tres años, y en cualquier caso de despido por discriminación que perturbe al trabajador víctima debido a su situación de adulto mayor, orientación sexual u otros casos no previstos en la ineficacia del despido, tendrá derecho a una indemnización compensatoria adicional, sin el restitución del trabajo y en el caso de despido injustificado de una persona con discapacidad, o de quien estuviere a cargo del sustento de una persona con discapacidad, esta indemnización compensatoria será la de un valor equivalente a dieciocho (18) meses de la mejor remuneración, adicionalmente de la indemnización legal que le corresponda, ordenada en el Art. 51 de la Ley Orgánica de Discapacidades y para el caso de supresión de puestos por necesidad institucional, no se considerarán los puestos que ocupen las personas con discapacidad o quienes tengan a su cuidado y responsabilidad un hijo, cónyuge, pareja en unión de hecho o progenitor con discapacidad, debidamente certificado por el Ministerio de Salud Pública, conocido como el Carnet del CONADIS.

Sobre el acoso laboral en materia penal se debe analizar el Art. 105 del COIP (Corporación de Estudios y Publicaciones, 2015), en el que se dispone que la persona que obligue a otra a realizar trabajos forzados o cualquier otra forma de explotación o servicio laboral, dentro o fuera del Ecuador, será sancionada con una pena privativa de libertad de diez a trece años, inclusive cuando se le obligue o mienta a una persona para que realice, contra su voluntad, un trabajo o servicio bajo coacción de producirle daño a ella o a terceras personas, también cuando se le fuerce a una persona a realizar un trabajo o servicio recurriendo a la violencia o amenaza o cuando se mande a una persona a prestar sus servicios lícitos y personales o los de alguien sobre quien ejerce autoridad en garantía de una deuda, aprovechándose de su condición de deudor calzando perfectamente con el acoso laboral, siendo denunciable a fiscalía para iniciar una investigación penal previa.

\subsection{Daños y perjuicios o daño moral laboral}

La víctima de acoso laboral, podría demandar el daños y perjuicios o daño moral causados por la actitud hostil, indolente o culposa del acosador, solicitando indemnizaciones fruto de relaciones contractuales y extracontractuales de trabajo, la Relación Contractual se da cuando surge de la ejecución del contrato laboral, y la Relación Extracontractual que surgen de las secuelas no vislumbradas, no sujetas o no reguladas en el contrato, pudiendo en el caso de relaciones contractuales laborales, manifestarse la inobservancia contractual presentando el contrato de trabajo, y en las relaciones extracontractuales laborales cuando se evidencie con pruebas complementarias sean estas testimoniales, periciales o documentales, la presunción de la existencia del daño cometido, con el solo fin de obtener la compensación monetaria indemnizatoria por daños y perjuicios causados a la víctima de acoso laboral, aunque muchas ocasiones el dinero no repara el daño psicológico causado, los jueces laborales debe dar un valor monetario al daño emergente y el lucro cesante causado para reparar el daño causado, ya sea que sí o no hayan afectado material e inmaterialmente a la víctima de acoso laboral. Cuando los perjuicios son patrimoniales el juez deberá fallar en torno al daño emergente y el lucro cesante causado, pero cuando el daño es psicológico, inmaterial o moral el juez podría fallar en torno a la afectación de la honra y la dignidad de la víctima acosada y en cuerda separada.

En cuanto al trámite este se da cuando se ha producido el despido ineficaz o el acoso laboral, el afectado podrá demandar ante uno de los Jueces del Trabajo del lugar donde este se produjo el hecho generador, en un plazo máximo de 30 días una vez admitida a trámite la demanda, se mandará a citar en el plazo de 24 horas a la parte empleadora y, en la misma providencia, se establecerá medidas cautelares que permitan el restitución inmediata al trabajo del trabajador afectado, mientras dure el trámite. A la demanda y a la contestación se le acompañarán las pruebas de que se disponga y se solicitarán las que deban practicarse y en la misma providencia fijándose día y hora para la audiencia, que se llevará a cabo en el plazo de 48 horas, contadas desde la citación. Esta iniciará por la conciliación y, de existir acuerdo, se autorizará a través de sentencia. A falta de acuerdo se practicarán las pruebas solicitadas, el Juez de Trabajo, para por fin dictarse sentencia en la misma audiencia, contra la sentencia que admita la ineficacia será admisible el recurso de apelación con efecto devolutivo, acción que debe seguirse en una de las salas provinciales de justicia.

\section{Conclusiones}

Las conclusiones a las que se puede llegar actualmente son que el Acoso Laboral en el Ecuador es muy sutil, casi imperceptible para el resto de trabajadores y las personas en general pero eso no significa que no exista y que no tenga sanciones judiciales, ya que para el acosado no es así porque sufre trastornos psicológicos y físicos inclusive afectando su estado de salud, afectando así su entorno social y jurídico, ya que uno de los deberes y políticas del estado Ecuatoriano es el de garantizar el buen vivir a los ecuatorianos erradicando todo daño que afecte la armonía social y la solidaridad social uno de esos daños es el acoso laboral y para ser considerado jurídicamente como una conducta ilícita en el Ecuador esta debe ser reiterada (Que se repite en varias ocasiones en un mismo tiempo), sistemática (Que sigue o se ajusta a un sistema) y demostrable (Que se puede demostrar), para así no confundir con otras figuras laborales parecidas, en el marco jurídico ecuatoriano vigente es más que evidente la existencia de un ordenamiento adecuado y capaz de frenar el acoso laboral, pero el problema que se a detectado en el acoso laboral, es la falta de información jurídica y las posibles medidas pre judiciales, judiciales o extrajudiciales que solucionen el problema del acoso laboral, para que prospere una denuncia por acoso 
laboral este debe ser reiterado, sistemático y demostrable, hay que tomar en cuenta que hasta la fecha no existe una sola denuncia de acoso laboral en la inspectoría de trabajo de la ciudad de Cuenca que haya prosperado positivamente, y esto a los acosadores laborales les conviene, ya que la ignorancia del tema acoso laboral por parte de las personas y la sociedad ecuatoriana también es su aliada, generando así un medio de cultivo propicio para que pulule este virus social, satisfaciendo el acosador todas sus bajas pasiones sin ningún tipo de sanción o restricción legal y social, por no saber cómo se da y cuándo se está frente al acoso laboral, pudiendo reclamar oportunamente sus derechos laborales vulnerados, por lo que es recomendable por ser una necesidad imperiosa el informar a la sociedad ecuatoriana a través de foros, publicaciones, simposios y cualquier otro medio de información sobre el tema de las estrategias jurídicas para afrontar el acoso laboral en el Ecuador, la cual debería ser a pequeña, mediana y gran escala a corto y mediano plazo, directa o indirectamente, para de esta manera frenar a los acosadores laborales generando a largo plazo un gran impacto positivo en el marco jurídico, político, social y económico de la sociedad ecuatoriana a la que pertenece la clase trabajadora nacional.

\section{Referencias Bibliográficas}

Asamblea Nacional del Ecuador. (2017). “Ley Orgánica Reformatoria a la Ley Orgánica del Servicio Público y al Código del Trabajo para Prevenir el Acoso Laboral". Quito - Ecuador.

Corporación de Estudios y Publicaciones. (2015). Código Orgánico Integral Penal. Quito - Ecuador.

Corporación de Estudios y Publicaciones. (2017). Código de Trabajo. Quito - Ecuador.

Piñuel, y Zabala, I. (2003). Mobbing: manual de autoayuda. Madrid - España: Editorial Aguilar.

World Health Organization. (1994). "ICD-10 International Classification of Diseases”. Geneva: American Psychiatric Publishing.

Recibido: 29 de abril de 2019

Aceptado: 13 de diciembre de 2020

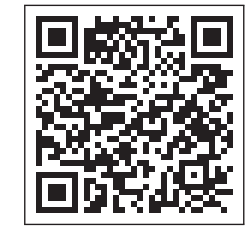

